\title{
Becoming British Columbia: A Population History
}

\author{
John Douglas Belshaw \\ Vancouver: UBC Press, 2009 \\ ISBN 978-0-774-81546-8 \\ $\$ 32.95,273$ pages \\ Reviewed by \\ Bill Marr \\ Wilfrid Laurier University \\ Waterloo, Ontario, Canada
}

John Belshaw's recent book about the population history of British Columbia in the $19^{\text {th }}$ and $20^{\text {th }}$ centuries is important and engaging. The book is important because brings together a wide reaching array of research and data about that province's demographic history in one book. It is engaging because, rather than only presenting those data, the author has also provided his interpretation of many of the patterns, trends, and swings that those demographic data seem to show. The book is well written and well organized with additional data in appendices, a useful set of notes, and suggestions for further reading.

Belshaw has organized his book in a fairly conventional way. There is an opening or introductory chapter, which is followed by a chapter that summarizes the demographic history of British Columbia over the two and a half centuries that this book emphasizes. That chapter is followed by a separate chapter for each of the sub-topics that we come to expect with any book about an area's population history, namely Aboriginal demographic change, nuptiality, fertility, immigration and internal migration, and mortality. The book's conclusion in the final chapter puts, in Belshaw's words, a Marxist perspective on the demographic history of British Columbia that is informed by feminism and post-colonial theory.

Briefly, there are several aspects of Belshaw's approach to the demographic history of British Columbia that are impressive and useful from a reader's perspective. First, the data and their interpretation are critically examined; this is most evident in Chapter 3 where he discusses Aboriginal population estimates, but can be found in many other places in the book. Second, and staying with the theme of data, the numbers that are used go beyond simply large aggregate data bases like the Public 
Use Microdata Samples, and include many disaggregated sources of data; this enables the reader to appreciate the complexity of this population history. Third, and related to that complexity, Belshaw makes excellent use of many specific examples within the province as he examines the fertility, mortality, and migration patterns of its demographic history. Fourth, differences in demographic patterns among various groups and across geographical areas are used effectively in the book; these include, for example, comparisons of Aboriginal to non-Aboriginal groups, more built up areas to rural areas, Asian ethnic origin peoples to non-Asian origin peoples, and British Columbia to other parts of Canada. These are used effectively to draw out the differences among various groups and regions. Related to this point, Belshaw employs data on Kamloops and Nanaimo throughout the book as specific examples of the province's population history; this provides unity to some of the comparisons that he makes. Fifth, Belshaw sets out, as he writes, to demonstrate that population, and its characteristics and changes, provide an important underlying structure for other aspects of British Columbia's society, including its economy; his approach provides a useful organizational basis for the presentation of data and for the discussion of what he finds in those data in each chapter of the book.

To be sure, there are a few places where minor quibbles can be raised about this study. It would have been useful to include other aspects of Aboriginal demographic history in Chapter 3; Belshaw mentions that many aspects of that history have been omitted there, but it would be useful to include it all in one place; other chapters do provide comparisons of the situation among Aboriginals with other demographic and spatial groups in British Columbia and elsewhere. As with most of us, Belshaw uses hyperbole in a few places when he wants to stress the importance of studying the population history of British Columbia. For example, he writes in Chapter 2 that most of the other Canadian provinces had less complicated immigration and succession histories than did British Columbia; where is the proof of that statement? This is also true in the final chapter where we read that British Columbia is at the extremes of the Western world's demographic trends, that British Columbia's demographic levels and trends are different from all other areas of Canada, and that Vancouver is unlike any other North American city. This all might be true, but more evidence is required.

John Belshaw's book is an important addition to the literature about British Columbia's population history and should be read by all people who are interested in Canada's demographic trends since the late $18^{\text {th }}$ century. It is also an entertaining read. 